\title{
Mean Square Cordial Labeling of Some Snake Graphs
}

\author{
S Dhanalakshmi, S Thirunavukkarasu, N Parvathi
}

\begin{abstract}
In this paper we investigate that some snake related graph admits mean square cordial labeling. In particular, mean square cordial labeling of a Triangular snake Tk, Subdivision of a triangular snake $S(T k)$, Quadrilateral snake QSk, Subdivision of a quadrilateral snake $S(Q S k)$ are discussed.
\end{abstract}

Index Terms: Mean square cordial labeling, Triangular snake, Subdivision of a triangular snake, Quadrilateral snake, Subdivision of a Quadrilateral snake.

\section{INTRODUCTION}

Numerous applications of graph labeling in real life induce the motivation among the researchers. Many research activities are tested from different types of graph labeling [1] which lead to many publications in this topic and the number of papers persists to be on the crease. In this work, there is a contribution of some interesting results on mean square cordial labeling. Snake related graphs are taken here for the discussion because these graphs are very common as a network design at the access layer of computer networks. Also snake related graphs are good models of network transits using probe tools like trace route. We follow Harary[2] for basic terminology and notations . Cahit[3] initiated the concept of cordial labeling .Mean cordial labeling was first studied by and Ponraj and et al[3].A.N. Murugan introduced the labeling technique of mean square cordial and they have investigated the same for some special graphs in [5,6,7] Dhanalakshmi et al explored some ideas on mean square cordial labeling of some acyclic graphs and its rough approximations[8] and projected the same labeling technique for some cyclic graphs[9]. In this paper we investigate that some snake related graph admits mean square cordial labeling. In particular, mean square cordial labeling of a Triangular snake Tk, Subdivision of a triangular snake S(Tk), Quadrilateral snake QSk, Subdivision of a quadrilateral snake $\mathrm{S}(\mathrm{QSk})$ are analysed.

\section{PRELIMINARIES}

Definition 1: Let $G=(V, E)$ be a graph with $p$ vertices and q edges. "A Mean Square Cordial labeling of a Graph G(V,E)

Revised Manuscript Received on July 22, 2019.

S Dhanalakshmi , Department of mathematics ,Faculty of Engineering andTechnology, SRM IST, Chennai -600089,India. Email:parvathn@srmist.edu.in

S Thirunavukkarasu, Department of Information Technology ,Faculty of Engineering and Technology, Bharath Institute of Higher Education and Research, Chennai -600073,India

N Parvathi, Department of mathematics, Faculty of Engineering and Technology SRM IST, Chennai -603203,India with $\mathrm{p}$ vertices and $\mathrm{q}$ edges is a bijection from $\mathrm{V}$ to

$\{0,1\}$ such that each edge uv is assigned the label where (ceil( $x)$ ) is the least integer greater than or equal to $x$ with the condition that the number of vertices labeled with 0 and the number of vertices labeled with 1 differ by at most 1 and the number of edges labeled with 0 and the number of edges labeled 0 and the number of edges labeled with 1 differ by at most $1 "$.

Definition 2: "A Triangular Snake TK is obtained from a path $\mathrm{u} 1, \mathrm{u} 2, \ldots \ldots$..uk by joining ui and ui+1 to a new vertex vi for $1 \leq \mathrm{i} \leq \mathrm{k}-1$. That is The triangular snake Tk is obtained from the path Pk by replacing each edge of the path by a triangle C3."

Definition 3: "The Quadrilateral snake $\mathrm{Q}(\mathrm{Sk})$ is obtained from a path $\mathrm{u} 1, \mathrm{u} 2, \ldots \ldots$..uk by joining ui and $u i+1$ for $1 \leq \mathrm{i} \leq$ $\mathrm{k}-1$, to two new vertices vi and wi and then joining vi and wi.That is the path Pn by replacing each edge of the path by a cycle C4."

Definition 4: "The pentagonal snake $\mathrm{P}(\mathrm{Sk})$ is obtained from a path $\mathrm{u} 1, \mathrm{u} 2, \ldots \ldots$.uk by joining ui and ui+1 for $1 \leq \mathrm{i} \leq$ $\mathrm{k}-1$, to two new vertices vi, wi, $\mathrm{xi}$ and then joining vi, $\mathrm{xi}$ and $x i$,wi.That is the path Pn by replacing each edge of the path by a cycle C5."'”

Definition 5: "Let $\mathrm{G}$ be a graph. The subdivision graph $S(G)$ is obtained from $G$ by subdividing each edge of $G$ with a vertex."

\section{MAIN RESULTS}

Theorem 1: Triangular snake $T_{k}$ admits mean square cordial labeling, $\forall k \geq 2$ Proof: Let $\mathrm{P}_{\mathrm{k}}$ be the path $\mathrm{u}_{1}, \mathrm{u}_{2}, \ldots, \mathrm{u}_{\mathrm{k}}$. Let $\mathrm{V}\left(\mathrm{T}_{\mathrm{k}}\right)=\mathrm{V}\left(\mathrm{P}_{\mathrm{k}}\right) \cup\left\{\mathrm{v}_{\mathrm{i}}\right.$, : i varies from 1 to $\mathrm{k}-1\} . \quad \mathrm{E}\left(\mathrm{T}_{\mathrm{k}}\right)=\left\{\left[\left(\mathrm{u}_{\mathrm{i}} \mathrm{u}_{\mathrm{i}+1}\right): \mathrm{i}\right.\right.$ varies from 1 to $\left.\mathrm{k}-1\right] \cup\left[\left(\mathrm{u}_{\mathrm{i}} \mathrm{v}_{\mathrm{i}}: \mathrm{i}\right.\right.$ varies from 1 to $\mathrm{k}-1\} \cup\left[\left(\mathrm{v}_{\mathrm{i}} \mathrm{u}_{\mathrm{i}+1}: \mathrm{i}\right.\right.$ varies from 1 to $\left.\mathrm{k}-1\right\}$ Here $|V|=2 k-1$ and $|E|=3 k-3$

Define $f$ maps $V\left(T_{k}\right)$ to $\{0,1\}$

Case (i) : For even k 
$f\left(u_{i}\right)=0, i$ varies from 1 to $k / 2$

$1, i$ varies $\operatorname{from}(k+2) / 2$ to $k$

$$
\begin{aligned}
f\left(v_{i}\right)= & 0, i \text { varies from } 1 \text { to } k / 2 \\
& 1, i \text { varies from }(k+2) / 2 \text { to } k-1
\end{aligned}
$$

Hence the edge labeling is

$$
\begin{aligned}
f\left(u_{i} u_{i+1}\right)= & 0, i \text { varies from } 1 \text { to }(k-2) / 2 \\
& 1, i \text { varies from } k / 2 \text { to } k-1
\end{aligned}
$$$$
f\left(u_{i} v_{i}\right)=0, i \text { varies from } 1 \text { to } k / 2
$$$$
1, i \text { varies from }(k+2) / 2 \text { to } k-1
$$

$f\left(u_{i+1} v_{i}\right)=0, i$ varies from 1 to $(k-2) / 2$

$$
1, i \text { varies from } k / 2 \text { to } k-1
$$

The above labeling pattern satisfied the cardinality of vertices and edges which are mentioned in the following table. In table, cardinality of vertices and edges are represented in terms of " $\mathrm{t}$ " throughout this section.

\begin{tabular}{|c|l|l|}
\hline $\mathbf{t}$ & $\mathbf{0}$ & $\mathbf{1}$ \\
\hline$\left|v_{f}(t)\right|$ & $k$ & $k-1$ \\
\hline$\left|e_{f}(t)\right|$ & $\frac{3 k}{2}-2$ & $\frac{3 k}{2}-1$ \\
\hline
\end{tabular}

Case (ii) : For odd $\mathbf{k}$

$f\left(u_{i}\right)=0, i$ varies from 1 to $(k+1) / 2$

$1, i$ varies from $(k+3) / 2$ to $k$

$f\left(v_{i}\right)=0, i$ varies from 1 to $(k-1) / 2$

$1, i$ varies from $(k+1) / 2$ to $k-1$

Hence the edge labeling is $f\left(u_{i} u_{i+1}\right)=0, i$ varies from 1 to $(k+1) / 2-1$

$1, i$ varies from $(k+1) / 2$ to $k-1$

$f\left(u_{i} v_{i}\right)=0, i$ varies from 1 to $(k-1) / 2$, $1, i$ varies $\operatorname{from}(k+1) / 2$ to $k-1$

$f\left(v_{i} u_{i+1}\right)=0, i$ varies from 1 to $(k+1) / 2-1$,

$1, i$ varies from $(k+1) / 2$ to $k-1$
OThe above labeling pattern satisfied the cardinality of vertices and edges which are mentioned in the following table.

\begin{tabular}{|c|l|l|}
\hline $\mathbf{t}$ & $\mathbf{0}$ & $\mathbf{1}$ \\
\hline$\left|v_{f}(t)\right|$ & $k$ & $k-1$ \\
\hline$\left|e_{f}(t)\right|$ & $\frac{3 k-3}{2}$ & $\frac{3 k-3}{2}$ \\
\hline
\end{tabular}

Hence the theorem is proved.

\section{Example:1}

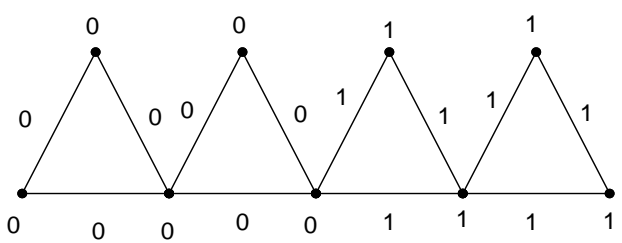

Figure (1) : Mean square cordial labeling of a triangular snakes $\mathrm{T}_{5}$

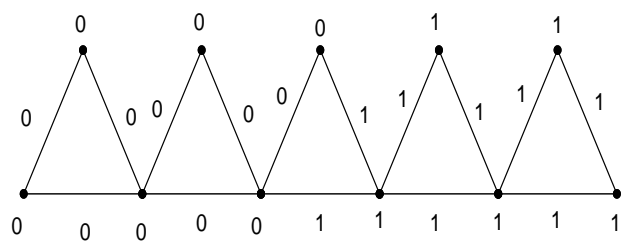

Figure (2) : Mean square cordial labeling of a triangular snakes $\mathrm{T}_{6}$

Theorem 2 :The subdivision of a triangular snake $S\left(T_{k}\right)$ admits mean square cordial

labeling, $\forall k \geq 3$ and $k$ is odd.

Proof: Let $\mathrm{P}_{\mathrm{k}}$ be the path $\mathrm{u}_{1}, \mathrm{u}_{2}, \ldots, \mathrm{u}_{\mathrm{k}}$. Let $\mathrm{V}\left(\mathrm{T}_{\mathrm{k}}\right)=$ $\mathrm{V}\left(\mathrm{P}_{\mathrm{k}}\right) \cup\left\{\mathrm{v}_{\mathrm{i}}: \mathrm{i}\right.$ varies from 1 to $\left.\mathrm{k}-1\right\}$ and $\mathrm{V}\left(\mathrm{S}\left(\mathrm{T}_{\mathrm{k}}\right)\right)=$ $\mathrm{V}\left(\mathrm{T}_{\mathrm{k}}\right) \cup\left\{\mathrm{x}_{\mathrm{i}}, \mathrm{y}_{\mathrm{i}}, \mathrm{w}_{\mathrm{i}}: \mathrm{i}\right.$ varies from 1 to $\left.\mathrm{k}-1\right\}$. Then $\mathrm{E}\left(\mathrm{S}\left(\mathrm{T}_{\mathrm{k}}\right)\right)=\left\{\left[\left(\mathrm{u}_{\mathrm{i}} \mathrm{x}_{\mathrm{i}}\right) \cup\left(\mathrm{x}_{\mathrm{i}} \mathrm{v}_{\mathrm{i}}\right) \cup\left(\mathrm{y}_{\mathrm{i}} \mathrm{v}_{\mathrm{i}}\right) \cup\left(\mathrm{y}_{\mathrm{i}} \mathrm{u}_{\mathrm{i}+1}\right) \cup\left(\mathrm{u}_{\mathrm{i}} \mathrm{W}_{\mathrm{i}}\right) \cup\right.\right.$ $\left(\mathrm{w}_{\mathrm{i}} \mathrm{u}_{\mathrm{i}+1}\right): \mathrm{i}$ varies from 1 to $\left.\mathrm{k}-1\right\}$

$$
\text { Here }|V|=5 k-4 \text { and }|E|=6 k-6
$$

Define f maps $\mathrm{V}\left(\mathrm{S}\left(\mathrm{T}_{\mathrm{k}}\right)\right)$ to $\{0,1\}$ $f\left(u_{i}\right)=0, i$ varies from 1 to $(k+1) / 2$ $1, i$ varies from $(k+3) / 2$ to $k$ 


$$
\begin{aligned}
f\left(v_{i}\right)= & 0, i \text { varies from } 1 \text { to }(k-1) / 2 \\
& 1, i \text { varies from }(k+1) / 2 \text { to } k-1 \\
f\left(x_{i}\right)= & 0, i \text { varies from } 1 \text { to }(k-1) / 2 \\
& 1, i \text { varies from }(k+1) / 2 \text { to } k-1 \\
f\left(y_{i}\right)= & 0, i \text { varies from } 1 \text { to }(k-1) / 2 \\
& 1, i \text { varies from }(k+1) / 2 \text { to } k-1 \\
f\left(w_{i}\right)= & 0, i \text { varies from } 1 \text { to }(k-1) / 2 \\
& 1, i \text { varies from }(k+1) / 2 \text { to } k-1
\end{aligned}
$$

Hence the edge labeling is

$$
\begin{aligned}
& f\left(u_{i} x_{i}\right)=0, i \text { varies from } 1 \text { to }(k-1) / 2 \text {, } \\
& 1, i \text { varies from }(k+1) / 2 \text { to } k-1 \text {, } \\
& f\left(x_{i} v_{i}\right)=0, i \text { varies from } 1 \text { to }(k-1) / 2 \text {, } \\
& 1, i \text { varies from }(k+1) / 2 \text { to } k-1 \text {, } \\
& f\left(v_{i} y_{i}\right)=0, i \text { varies from } 1 \text { to }(k-1) / 2 \text {, } \\
& 1, i \text { varies from }(k+1) / 2 \text { to } k-1 \text {, } \\
& f\left(u_{i} w_{i}\right)=0, i \text { varies from } 1 \text { to }(k-1) / 2 \text {, } \\
& 1, i \text { varies from }(k+1) / 2 \text { to } k-1 \text {, } \\
& f\left(u_{i} w_{i}\right)=0, i \text { varies from } 1 \text { to }(k-1) / 2 \text {, } \\
& 1, i \text { varies from }(k+1) / 2 \text { to } k-1 \text {, } \\
& f\left(u_{i+1} w_{i}\right)=0, i \text { varies from } 1 \text { to }(k-1) / 2 \text {, } \\
& 1, i \text { varies from }(k+1) / 2 \text { to } k-1 \text {, } \\
& f\left(u_{i+1} y_{i}\right)=0, i \text { varies from } 1 \text { to }(k-1) / 2 \text {, } \\
& 1, i \text { varies from }(k+1) / 2 \text { to } k-1 \text {, }
\end{aligned}
$$

The above labeling pattern satisfied the cardinality of vertices and edges which are mentioned in the following table.

\begin{tabular}{|c|l|l|}
\hline $\mathbf{t}$ & $\mathbf{0}$ & $\mathbf{1}$ \\
\hline$\left|v_{f}(t)\right|$ & $\frac{5 k-3}{2}$ & $\frac{5 k-5}{2}$ \\
\hline$\left|e_{f}(t)\right|$ & $3 k-3$ & $3 k-3$ \\
\hline
\end{tabular}

Hence the theorem is proved.

\section{Example: 2}

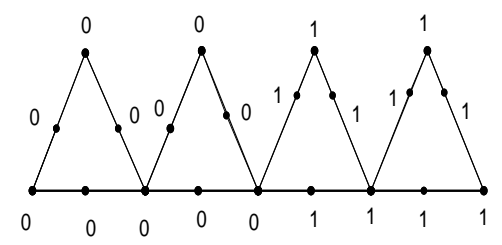

Figure (3) : Mean square cordial labeling of subdivision of a triangular snakes $\mathrm{S}\left(\mathrm{T}_{5}\right)$

Remark 1: Subdivision triangular snake $S\left(\mathrm{~T}_{\mathrm{k}}\right)$ doesn't satify the above labeling for even value of $\mathrm{k}$ since the edge difference labeled with 0 and 1 is two, contradicts the edge condition of mean square cordial labeling.

\section{Theorem 3: Quadrilateral snake $\mathbf{Q S}_{\mathbf{k}}$ admits mean square cordial labeling, $\forall k \geq 3$, $k$ is odd}

Proof: Let $\mathrm{P}_{\mathrm{k}}$ be the path $\mathrm{u}_{1}, \mathrm{u}_{2}, \ldots, \mathrm{u}_{\mathrm{k}}$. Let $\mathrm{V}\left(\mathrm{QS}_{\mathrm{k}}\right)=$ $\mathrm{V}\left(\mathrm{P}_{\mathrm{k}}\right) \cup\left\{\mathrm{v}_{\mathrm{i}}, \mathrm{w}_{\mathrm{i}}: \mathrm{i}\right.$ varies from 1 to $\left.\mathrm{k}-1\right\} . \quad \mathrm{E}\left(\mathrm{Q} \mathrm{S}_{\mathrm{k}}\right)=\left\{\left[\left(\mathrm{u}_{\mathrm{i}} \mathrm{u}_{\mathrm{i}+1}\right): \mathrm{i}\right.\right.$ varies from 1 to $\mathrm{k}-1] \cup\left[\left(\mathrm{u}_{\mathrm{i}} \mathrm{v}_{\mathrm{i}}: \mathrm{i}\right.\right.$ varies from 1 to $\left.\mathrm{k}-1\right\} \cup$

$\left[\left(\mathrm{v}_{\mathrm{i}} \mathrm{W}_{\mathrm{i}}: \mathrm{i}\right.\right.$ varies from 1 to $\left.\mathrm{k}-1\right] \cup\left[\left(\mathrm{w}_{\mathrm{i}} \mathrm{u}_{\mathrm{i}+1}: \mathrm{i}\right.\right.$ varies from 1 to k-1 \}

Here $|V|=3 k-2$ and $|E|=4 k-4$

Define $\mathrm{f}$ maps $\mathrm{V}\left(\mathrm{Q} \mathrm{S}_{\mathrm{k}}\right)$ to $\{0,1\}$

$$
f\left(u_{i}\right)=0, i \text { varies from } 1 \text { to }(k+1) / 2
$$

$$
1, i \text { varies from }(k+3) / 2 \text { to } k
$$

$$
\begin{aligned}
f\left(v_{i}\right)= & 0, i \text { varies from } 1 \text { to }(k-1) / 2 \\
& 1, i \text { varies from }(k+1) / 2 \text { to } k-1
\end{aligned}
$$

$$
\begin{aligned}
f\left(w_{i}\right)= & 0, i \text { varies from } 1 \text { to }(k-1) / 2 \\
& 1, i \text { varies from }(k+1) / 2 \text { to } k-1
\end{aligned}
$$

Hence the edge labeling is

$$
\begin{aligned}
& f\left(u_{i} u_{i+1}\right)=0, i \text { varies from } 1 \text { to }(k-1) / 2 \\
& 1, i \text { varies from }(k+1) / 2 \text { to } k-1 \\
& f\left(u_{i} v_{i}\right)=0, i \text { varies from } 1 \text { to }(k-1) / 2 \text {, } \\
& 1, i \text { varies from }(k+1) / 2 \text { to } k-1 \text {, } \\
& f\left(v_{i} w_{i}\right)=0, i \text { varies from } 1 \text { to }(k-1) / 2 \\
& 1, i \text { varies from }(k+1) / 2 \text { to } k-1, \\
& f\left(u_{i+1} w_{i}\right)=0, i \text { varies from } 1 \text { to }(k-1) / 2 \\
& 1, i \text { varies from }(k+1) / 2 \text { to } k-1 \text {, }
\end{aligned}
$$

The above labeling pattern satisfied the cardinality of vertices and edges which are mentioned in the following table. 


\begin{tabular}{|c|l|l|}
\hline & $\mathbf{0}$ & $\mathbf{1}$ \\
\hline$\left|v_{f}(t)\right|$ & $\frac{3 k-1}{2}$ & $\frac{3 k-3}{2}$ \\
\cline { 1 - 2 }$\left|e_{f}(t)\right|$ & $\frac{4 k-4}{2}$ & $\frac{4 k-4}{2}$ \\
\hline
\end{tabular}

Hence the theorem is proved.

\section{Example:3}

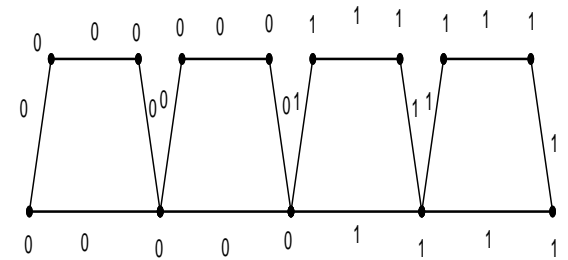

Figure (4): Mean square cordial labeling of a quadrilateral snake $\mathrm{QS}_{5}$

Remark 2: Quadrilateral snake $\mathrm{QS}_{\mathrm{k}}$ doesn't satify the above labeling for even value of $\mathrm{k}$ since the edge difference labeled with 0 and 1 is two, contradicts the edge condition of mean square cordial labeling.

Theorem: 4 Subdivision of a quadrilateral snake $S\left(Q_{\mathrm{k}}\right)$ admits mean square cordial labeling,

$\forall k \geq 3$ and $k$ is odd .

Proof: Let $\mathrm{P}_{\mathrm{k}}$ be the path $\mathrm{u}_{1}, \mathrm{u}_{2}, \ldots, \mathrm{u}_{\mathrm{k}}$. Let $\mathrm{V}\left(\mathrm{QS}_{\mathrm{k}}\right)=$ $\mathrm{V}\left(\mathrm{P}_{\mathrm{k}}\right) \cup\left\{\mathrm{v}_{\mathrm{i}}, \mathrm{w}_{\mathrm{i}}: \mathrm{i}\right.$ varies from 1 to $\left.\mathrm{k}-1\right\}$ and $\mathrm{V}\left(\mathrm{S}\left(\mathrm{QS}_{\mathrm{k}}\right)\right)=$ $\mathrm{V}\left(\mathrm{QS}_{\mathrm{k}}\right) \cup\left\{\mathrm{x}_{\mathrm{i}}, \mathrm{y}_{\mathrm{i}}, \mathrm{z}_{\mathrm{i}}, \mathrm{p}_{\mathrm{i}}: \mathrm{i}\right.$ varies from 1 to k-1 $\}$ Then $\mathrm{E}\left(\mathrm{S}\left(\mathrm{QS}_{\mathrm{k}}\right)\right)$ $=\left\{\left[\left(\mathrm{u}_{\mathrm{i}} \mathrm{x}_{\mathrm{i}}\right): \mathrm{i}\right.\right.$ varies from 1 to $\left.\mathrm{k}-1\right] \cup\left[\left(\mathrm{v}_{\mathrm{i}} \mathrm{x}_{\mathrm{i}}\right): \mathrm{i}\right.$ varies from 1 to $\mathrm{k}-1] \cup\left[\left(\mathrm{v}_{\mathrm{i}} \mathrm{y}_{\mathrm{i}}\right.\right.$ : $\mathrm{i}$ varies from 1 to $\left.\mathrm{k}-1\right] \cup\left[\left(\mathrm{y}_{\mathrm{i}} \mathrm{w}_{\mathrm{i}}: \mathrm{i}\right.\right.$ varies from 1 to $\mathrm{k}-1] \cup\left[\left(\mathrm{z}_{\mathrm{i}} \mathrm{w}_{\mathrm{i}}: \mathrm{i}\right.\right.$ varies from 1 to $\left.\mathrm{k}-1\right] \cup\left[\left(\mathrm{z}_{\mathrm{i}} \mathrm{u}_{\mathrm{i}+1}: \mathrm{i}\right.\right.$ varies from 1 to $\mathrm{k}-1 \cup\left[\left(\mathrm{p}_{\mathrm{i}} \mathrm{u}_{\mathrm{i}+1}\right.\right.$ : $\mathrm{i}$ varies from 1 to $\mathrm{k}-1 \cup\left[\left(\mathrm{p}_{\mathrm{i}} \mathrm{u}_{\mathrm{i}}\right.\right.$ : $\mathrm{i}$ varies from 1 to $\mathrm{k}-1$ \}

Here $|V|=7 k-6$ and $|E|=7 k-3$

Define $\mathrm{f}$ maps $\mathrm{V}\left(\mathrm{S}\left(\mathrm{QS}_{\mathrm{k}}\right)\right)$ to $\{0,1\}$

$f\left(u_{i}\right)=0, i$ varies from 1 to $(k+1) / 2$

$1, i$ varies from $(k+3) / 2$ to $k$

$f\left(v_{i}\right)=0, i$ varies from 1 to $(k-1) / 2$

$1, i$ varies from $(k+1) / 2$ to $k-1$

$f\left(w_{i}\right)=0, i$ varies from 1 to $(k-1) / 2$

$1, i$ varies from $(k+1) / 2$ to $k-1$

$f\left(x_{i}\right)=0, i$ varies from 1 to $(k-1) / 2$

$1, i$ varies from $(k+1) / 2$ to $k-1$

$f\left(y_{i}\right)=0, i$ varies from 1 to $(k-1) / 2$

$1, i$ varies from $(k+1) / 2$ to $k-1$

$$
\begin{aligned}
f\left(z_{i}\right)= & 0, i \text { varies from } 1 \text { to }(k-1) / 2 \\
& 1, i \text { varies from }(k+1) / 2 \text { to } k-1 \\
f\left(p_{i}\right)= & 0, i \text { varies from } 1 \text { to }(k-1) / 2 \\
& 1, i \text { varies from }(k+1) / 2 \text { to } k-1
\end{aligned}
$$

Hence the edge labeling is

$f\left(u_{i} x_{i}\right)=0, i$ varies from 1 to $(k-1) / 2$,

$1, i$ varies from $(k+1) / 2$ to $k-1$,

$f\left(x_{i} v_{i}\right)=0, i$ varies from 1 to $(k-1) / 2$,

$1, i$ varies from $(k+1) / 2$ to $k-1$

$f\left(v_{i} y_{i}\right)=0, i$ varies from 1 to $(k-1) / 2$,

$1, i$ varies from $(k+1) / 2$ to $k-1$

$f\left(y_{i} w_{i}\right)=0, i$ varies from 1 to $(k-1) / 2$,

$1, i$ varies from $(k+1) / 2$ to $k-1$

$f\left(w_{i} z_{i}\right)=0, i$ varies from 1 to $(k-1) / 2$,

$1, i$ varies from $(k+1) / 2$ to $k-1$

$f\left(z_{i} u_{i+1}\right)=0, i$ varies from 1 to $(k-1) / 2$,

$1, i$ varies from $(k+1) / 2$ to $k-1$

$f\left(u_{i+1} p_{i}\right)=0, i$ varies from 1 to $(k-1) / 2$,

$1, i$ varies from $(k+1) / 2$ to $k-1$

$f\left(p_{i} u_{i}\right)=0, i$ varies from 1 to $(k-1) / 2$,

$1, i$ varies from $(k+1) / 2$ to $k-1$

The above labeling pattern satisfied the cardinality of vertices and edges which are mentioned in the following table. 


\begin{tabular}{|l|l|l|}
\hline $\mathbf{t}$ & $\mathbf{0}$ & $\mathbf{1}$ \\
\hline$\left|v_{f}(t)\right|$ & $\frac{7 k-5}{2}$ & $\frac{7 k-7}{2}$ \\
\hline$\left|e_{f}(t)\right|$ & $\frac{7 k-3}{2}$ & $\frac{7 k-3}{2}$ \\
\hline
\end{tabular}

Hence the theorem is proved.

Example: 4

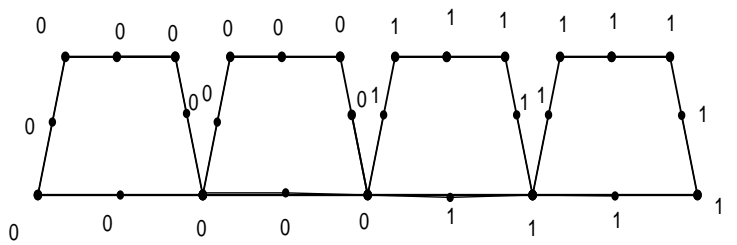

Figure (5): Mean square cordial labeling of $\mathrm{S}\left(\mathrm{QS}_{5}\right)$

Remark 3: Subdivision of quadrilateral snake $\mathrm{S}\left(\mathrm{Q} \mathrm{S}_{\mathrm{k}}\right)$ doesn't satify the mean square cordial labeling for even value of $\mathrm{k}$ since the edge difference labeled with 0 and 1 is two, contradicts the edge condition of mean square cordial labeling.

\section{CONCLUSION}

In this section mean square cordial labeling is investigated for some snake related graphs. It can be further investigated by the researcher for some more snake related graphs like alternate triangular snake graphs, double triangular snake graphs, alternate quadrilateral snake graphs, double quadrilateral graphs etc. Graph operations like union, intersection, corona of two graphs etc., can also be discussed for mean square cordial labeling in future.

\section{ACKNOWLEDGMENT}

We offer our sincere thanks to the referee for the valuable suggestion for revision of the paper.

\section{REFERENCES}

[1] A. Gallian A Dynamic Survey of Graph Labeling Electronic Journal of Combinatorics, Vol. 18, 2011, pp. 1-219

[2] F. Harary Graph Theory Narosa Publishing House, New Delhi, 1988.

[3] I.Cahit Cordial Graphs: A Weaker Version of Graceful and Harmonious Graphs Ars Combinatoria, Vol. 23, No. 3, 1987, pp. 201-207.

[4] Ponraj, M.Sivakumar and M.Sundaram, Mean cordial labeling of graphs ,Open journal of Discrete Mathematics, 2(4)(2012), 145-14

[5] A.Nellai Murugan, S.Heerajohn Special Class of Mean Square Cordial Graphs, International Journal of Applied Research 2015; 1(11): 128-131

[6] A.Nellai Murugan, S.Heerajohn Tree Related Mean Square Cordial Graphs ,outreach IX 2016 126-131 ,A multidisciplinary refereed journal
[7] A.Nellai Murugan, S.Heerajohn Cycle related of Mean Square Cordial Graphs, International Journal of research and development organization.

[8] S.Dhanalakshmi and N.Parvathi Mean square cordial labelling related to some acyclic graphs and its rough approximations , National Conference on Mathematical Techniques and its Applications (NCMTA 18) IOP Publishing IOP Conf. Series: Journal of Physics: Conf. Series 1000 (2018) 012040 doi :10.1088/1742-6596/1000/1/01204

[9] S.Dhanalakshmi and N.Parvathi Mean square cordial labeling of some cycle related graphs, International Journal on Science and Technology,7 (4.10) (2018)797-800 Website:www.sciencepubco.com/index.php/IJET

\section{AUTHORS PROFILE}

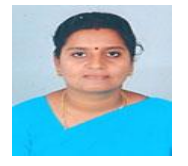

Mrs.S.Dhanalakshmi received her Bachelor's degree in Mathematics in 1999 from TKGA College. She completed her M.Sc. in Annamalai university and M.Phil. in Alagappa university. She is pursuing Ph.D in the field of graph theory at SRMIST ,Kattankulthur.She has attended and presented several international and national conferences and published eight papers in national and international journals. At present, she is working as an Assistant Professor in the Department of Mathematics, SRM Institute of Science and Technology, Ramapuram, Tamil Nadu, with more than fourteen years of teaching experience

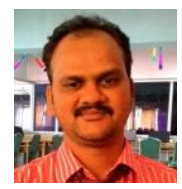

Mr.S.Thirunavukkarasu received Bachelor's degree in Mathematics in 1999 fro TKGAC, Vriddhachalam. She completed her M.Sc. in Annamalai university and M.Phil. in Alagappa university. She is pursuing Ph.D in the field of graph theory at SRMIST ,Kattankulthur.She has attended and presented several international and national conferences and published eight papers in national and international journals. At present, she is working as an Assistant Professor in the Department of Mathematics, SRM Institute of Science and Technology, Ramapuram, Tamil Nadu, with more than fourteen years of teaching experience

Dr.N.Parvathi completed B.Sc. and M.Sc Mathematics at Madurai Kamaraj University in the year 1989 and 1991. She completed M.Phil. at Bharathidasan university and M.C.A. at Manonmaniam Sundaranar university in the year 1995 and 2003. Also she obtained $\mathrm{Ph} . \mathrm{D}$ degree in the field of graph theory at Bharathidasan university in the year 2007.Under her guidance, one student completed Ph.D degree and presently she is guiding eight research scholars. She has attended and presented papers in several international and national conferences and published thirty papers in scopus indexed journals. At present, she is working as a Professor in the Department of Mathematics, Faculty of Engineering and Technology, SRM Institute of Science and Technology, Kattankulathur, Tamil Nadu, with more than twenty five years of teaching experience 